operation any but the slightest friction in attempting to procure the removal of the cyst. Some pain for an hour or two after the operation. Adhesions, and many cysts, with thickened walls, existed. Opium, and bandage, employed. Perfect recovery; not cured; she was sitting up and dressed on the fourth day after the operation.- $[\mathrm{Mr}$. Hargraves kindly invited me to witness this operation, and has allowed me to insert this report of it.]

X. Operation performed in Guy's Hospital in 1839.-Ovarian tumour; fluctuation distinct; health tolerable. The operation in this case was not the same as that advocated in the foregoing paper, more traction being made at the cyst, and more internal exploration, There was slight adhesion. She sank. LThe cyst was not removed in this case. The post mortem examination seemed to throw much light as to the cause; for it appeared, on laying open the abdomen, that the first cyst was in connection with a second, of nearly, if not quite, the same magnitude. The cavities of the two were not, however, in communication with each other. Probably, if this non-punctured cyst had been discovered, by making the incision a little longer, a less degree of traction would have been used, and with a more favourable result.]

\section{GENERAL INFIRMARY, HERTFORD.}

FRACTURE OF THE BASE OF THE SKULL-LESION OF THE SEVENTH NERVE, POLLOWED BY PARALYSIS OF ONE SIDE OF THE FACE-SUICIDE FIVE MONTHS AFTER THE INJURY-AUTOPSY.

\section{By John Daries, Esq., Surgeon.}

Jos. BY voth, aged 31, a tall, fine-looking man, was brought into the General Infirmary, under my care, on the 1st May last, 1839. When brought in he was perfectly insensible, and bleeding copiously from the ears, nose, and mouth. The account given of the accident was, that the man was either standing or sitting on the shaft of a cart loaded with gravel, when the cart tilted back and pitched him over on his head, which rendered him at once insensible. Soon after his admission his sensibility began to return, and, under the usual antiphlogistic plan of treatment, he recovered so far that, at his own request, he was discharged on the 9 th of the same month. In fact, no serious symptom showed itself after the return of sensibility.

The effects of the accident were the following:-Perfect insensibility for about an hour, during which time the bleeding from the nose and ears, particularly the left, was very copions; then a gradual return of sensibility, and cessation of bleeding; no frac- ture could be discovered in any part of the skull, though it was suspected that its base was fractured; the mouth drawn slightly towards the right side; deafness of the left ear; a sort of singing or hissing noise in the head; these were the only symptoms of cerebral lesion discovered while the man remained in the hospital. The normal signs were-absence of all delirium and of mental disturbance; pupils of the eyes natural ; pulse moderate, and non-occurrence of any febrile symptoms; sleep natural ; in a word, the absence, up to the time of his leaving the infirmary, of any symptoms indicating severe lesion of the brain.

When I visited the patient a few days after he had left the infirmary, I noted the following symptoms, which were not all discovered whilst he was lying in bed at the hospital:-The month was drawn considerably to the right side; total absence of the power of motion of the left side of the face; sense of feeling equally natural on both sides; an attempt at smiling caused a rery ridiculous appearance of the countenance; it gave you the idea of a person having two faces, one smiling at you, while the other was staring at you with the most profound gravity; the right side of the forehead presented the natural wrinkling of the skin, while the left looked quite smooth, and no effort could induce it to change its appearance; the left ala of the nose fell in upon the septum narium, and the man said that he was occasionally obliged to take hold of that side of the nose and pull it open; in eating and drinking he was conscious that he possessed no power over the left side of the face, because when the food got between the cheek and the gums, he was obliged to introduce his finger to scoop it out, and he could not drink, he said, without closing the left side of his mouth with his hand, or by applying the cup to that side, and iuclining his head to the right, for the fluid ran ont at the left angle of the mouth; he could not close his left eye; no effort could enable him to make the eye-lids ap. proach each other. When told to shut his eyes, the right one was immediately closed, and the pupil of the left was at the same instant whipped up uader the upper lid, but leaving the lids perfectly open, so as to expose the white of the eye; he was not at all conscious that the left eye did not shnt at the same time as. the right, but he suid " he thought there must be something wrong about his eyes, because bis wife told him that he never slept ;" no portion of the cornea of the left eye was visible when the right was closed; and, according to bis account, the one was in total darkness equal to the other; he felt no inconvenience from the inability to close the eye-lids, for the eye was not at all inflamed.

All the above symptoms continued the same, and of the same degree, up to the time 
of the man's death, which took place, as shall be immediately described, just five montbs after the accident. I had several opportunities of noticing them, and of causing the experiments on the eye to be repeated. The noise in the bead, with a slight discharge from the left ear, lasted for about four months ; but what is rather remarkable is, that, according to his own account, the hearing of the left ear, which was at first destroyed by the accident, returned after about a month, and that of the right ear became extinct, or considerably diminished. During the last three months, he frequently, in my presence, applied his watch to his ears, and declared that he could hear it tick very well with his left, but that he could not hear it with his right.

The man remained for about four months without returaing to his work, but he worked at the harvest, Sic., during the last four or five weeks.

The opinion which I extertained of the case, and which I expressed to several me. dical friends, was, that the basis of the skull had been fractured by the accident, which was rendered probable by the copious hamorrhage from the cars and nose, though no grave symptoms of cerebral derangement occurred after the concussion caused by the fall; that the fracture had either occasioned a rupture of the portio dura of the seventh cerebral nerve, or produced a permanent pressure upon gome part of it in its passige through the bone; or else that extravasated blood pressed upon some part of its course within the cranium. The symptoms, after the first effect of the concussion produced by the fall, were exactly those so graphically described by Sir Charles Bell, as proceeding from destruction of the function of the portio dura of the seventh cerebral nerve.

In the night of the 30th Sept. last, By. noth, having suffered for three or four days from the prevailing bowel complaint, exhibited, all of a sudden, symptoms of delirium, occasiuned in a measure, it was supposed, by some unpleasant family affairs, comnitted suicide, by cutting his throat with a razor. He lived about thirty hours after committing the act. I had seen bim in the morning of the same day: he theu appeared much as usual.

On post mortem examination, at which I was assisted by my friend Mr. Shillitoe, of this town, the bones of the cranium were found unusually thin; all the membranes of the brain appeared perfectly healthy, with the exception of a slight turbidity of that portion of the arachnoid situated in the left middle fossa. The brain itself was remarkably bloodless, of the natural consistence, and presenting all the appearance of a healthy brain. In the left temporal bone there were the remains of a fracture, running obliquely backwards and outwards, between the squamous and petrous portions, splitting the Enstachian canal as far as the tympa. num; then continuing on, partly separating the squamous portion of the temporal from the parietal bone. At the root of the petrous portion, there was a transverse branch of the fracture, extending across from the tympanum to the groove of the lateral sinus; thus dividing the Fallopian canal, along which the portio dura of the nerve of the seventh pair finds its passage out of the skull. The fracture was so slightly united, that the mere vibration caused by sawing the bone, occasioned it to separate. This circumstance was rather singular, considering that five months had elapsed since the accident ; but, in fact, all the bones of the cranium, besides being very thin, appeared more brittle than usual. The lateral sinus had not been injured, or, if it had, no indication of injury remained observable after death.

The points most remarkable in this case are-I st., that so extensive an injury should have caused such slight cerebral derangement; 2nd, that the case affords an additional illustration of the correctness of Sir Charles Bell's views, respecting the function of the nerve of the seventh pair; 3rd, the loss of hearing, first of the car on the side of the injury, afterwards of the ear of the opposite side, but with a return of hearing on the sinle originally affected. The loss of bearing on the side of the injury might have been occa. sioned by extrarasated blood blocking up the passage,so as to prevent the sound from reach. ing the auditory nerve, and its resturation, have taken place from the absorption or discharge of the obstacle; but it is not so easy to account for the fact that deafness occurred in the opposite car a mouth after the accident.

Fractures of the base of the skull are generally considered fatal; but I see no reason why they should necessarily prore so, as simple fractures, any more than fractures of any other part of the cranium. It is here that the violence which produces a mere fissuro in the base of the shull may also occasion a rupture of the lateral sinus, or of a considerable branch of the cerebral arteries, or cause some other severe lesion of the contents of the cranium, so as to lead to a fatal result; but so may a mere fissure in the region of the priocipal meningeal artery cause a rupture of that vessel, and thereby occasion death, upon the same principle; namely, by producing pressure upon the braid.

Judging from symptoms, I have reason to believe that I have witnessed three or four cases of fracture of the base of the skull, where the patients recovered, but none of them with so little cerebral disturbance as the subject of this paper.

Hertford, Oct. 10, 1839: 